\title{
Making publication more respectable
}

\section{The benefits of weakening the link between publication and personal success would be immense, and the place to start is with the widespread practice of spurious co-authorship.}

How and when will it be possible to arrange that researchers' personal success (and their families' general comfort) can be separated from their publications records? Last week, this journal argued for a deliberate weakening of the link in the belief that the tendency to misuse the literature, and in particular to use it as a means of acquiring a false reputation as a productive researcher, would thereby be diminished (see Nature 369, 261 $262 ; 1994)$. But the research profession is by now so accustomed to the use of publications as indicators of personal performance that there may be some who do not think the project feasible.

Nothing in what follows, which is meant to demonstrate that a weaker link is feasible as well as desirable, should be mistaken for a diatribe against the process of publication as such. Where, after all, would Nature be if people never published written accounts of what they had done? Where, for that matter, would science itself be? A discovery, after all, is no better and no worse than the written account of it eventually appearing in the literature (some of which may well be electronic soon).

But the case for a weaker link is not simply to diminish the incentive for outrageous fraud. On the contrary, the outright fabrication of data that are then woven into a convincing tale, which is almost always a lonely business exercised in seclusion from potentially critical colleagues, would probably continue. (Vanity is a powerful force.) But imaginative people of that kind would not so easily win the patronage of more senior people who are themselves genuinely too busy for research, but who are too proud to say so and who dare, as a consequence, to run the risks to their reputations of coauthorship in work they do not understand.

Indeed, the general interest is that honorary co-authorship as such should be reduced, and not simply for the convenience of the managers of the databases now storing all the names in the literature. For historical purposes, as well as to know who did what, it is important that the authors of publications should in some meaningful sense be jointly and severally responsible for the content of what is published. Can that be the case when the number of the authors of an account of a particle accelerator experiment may easily exceed a hundred or two?

To single out these extremes is not to suggest that the majority of the authors have been sleeping partners. In the nature of accelerator experiments, most of the army NATURE · VOL $369 \cdot 2$ JUNE 1994 of authors will have made vital, but often very particular, contributions to the joint enterprise. But the inclusion of their names in such a list of authors does not help users of the literature to appreciate what they have done, and how well, while their prospects of personal advancement will depend almost exclusively on the opinions formed by group leaders and other senior people of their work. In other words, in these extreme cases, a person's appearance in a list of authors hardly matters, but his colleagues' appraisal does.

As it happens, co-authorship is as serious an anxiety in biology. Does it, for example, make sense that physicians who have collected blood from their patients for some collaborative study should appear as authors of the account eventually published of it? Or what is the proper form of acknowledgement for assistance when a person has complied with the conventions of the research trade, and has supplied others with some essential research material? Some journals (but not this one) make it an absolute condition of publication that research materials used will be made available to all serious enquirers. What do they have to say about the practice of suppliers who insist on co-authorship as a quid pro quo?

Of course, a person who has supplied some material essential for an investigation, a DNA clone containing a novel gene perhaps, may claim to have made an essential contribution, but if the material arose in the course of an investigation already published, is it necessary, let alone equitable, that he or she should have a second bite at the cherry of credit? Those who look to the published record for a measure of people's productivity as researchers may be dismayed to learn that personal lustre can be a matter for crude negotiation along these lines.

Worse can happen. One of Nature's authors has recently been downcast to learn that two people who had kindly helped to supply the material that was the subject of an investigation had less kindly supplied the same material to a larger group elsewhere, but without disclosing that circumstance. The result will be two nearly simultaneous publications in two different journals, with (probably) two sets of co-authorship for the zealous suppliers. It is not difficult to guess what this kind of happening does for the civility of the research enterprise.

It is more difficult to decide on a workable antidote for the abuse of co-authorship. The principle is that every listed author should at least be able to give a brief talk at a public meeting on the substance of what had been reported in writing. He or she would be forgiven if some of the questions raised in the discussion required the presence of a colleague specialized in one or other of the specialized techniques involved, but not for failing to describe the antecedents of the work or to give a coherent account of the result and its importance.

Sadly, there are no easy written tests of this distribution of responsibility among the authors of manuscripts submitted for publication. The benefits of authorship are so great that potential authors of manuscripts awaiting publication would probably, without hesitation, sign formal declarations that they had been full members of the group responsible. And the prospects are slender of carrying through a scheme advocated some years ago by some editors of journals that credit should be apportioned among authors by decimal fractions adding up to 1.0 for each published article. A better first step would be that authors themselves should include a brief statement in their text of who did what when a piece of work has involved the collaboration of people with different skills.

Ridding the literature of spurious coauthorship is regrettably only a small part of what needs to be done if the literature is to become a record of discovery, not just a curriculum vitae for every working scientist. But there are some lessons to be learned from even a cursory consideration of that task.

Not the least of them is the recognition that, among the small armies of people who dance attendance on particle accelerator experiments, the presence of a name among the many authors of a publication can only be an unhelpful guide to that person's quality and potential as a researcher, and that the opinions of others on these points must be crucial to that person's career. There is much to be said for extending that practice more widely, to fields in which the difficulty of knowing who did what, and how well, is not the mere number of authors at the head of a publication, but the certain presence therein of spurious co-authors.

The obvious danger is that nepotism or even prejudice may then have an influence, but one of the benefits of the present universal competition for research funds is that only the short-sighted would fail to resist those influences. In short, the disappearance of spurious co-authors would help enormously in dealing with the appointment and promotion of people to research posts. The competition for research grants is a more difficult problem. John Maddox 